\title{
The inability of young children to reproduce intensity differences in musical rhythms
}

\author{
CLAIRE GERARD and CAROLYN DRAKE \\ Laboratoire de Psychologie Expérimentale, CNRS, Paris, France
}

\begin{abstract}
A musical rhythm can be described in terms of both its temporal and its dynamic structure. However, although 6-year-old children are able to perceive and reproduce simple temporal structures, even 8-year-olds rarely reproduce intensity differences. Four experiments on the perception and reproduction of musical rhythms by 5 - to 8 -year-old children demonstrate that even though dynamic structure is clearly dominated by its temporal support, intensity differences play a role in reinforcing the temporal structure. The inability of children to reproduce intensity differences appears to be due neither to an inability to control the intensity of their tap responses nor to the fact that they cannot perceive such changes in intensity. Rather, the results seem best interpreted in terms of the allocation of attentional resources. With simple stimulus material (Experiments 1-3), the children focused on temporal information, and only when the processing of temporal information was mastered did they have "enough attention left" to direct it to intensity differences (Experiment 2). With more complex orchestral music (Experiment 4), attention was primarily allocated to the dynamic structure.
\end{abstract}

Psychologists concerned with the perception of music have tended to concentrate on either melodic or temporal aspects of the auditory sequence. The last few years, however, have seen the appearance of studies of the relation between the two, with two main explanations emerging. As for the first, Jones $(1976,1987)$ has proposed a model of perceptual interaction, in which perceived temporal structure affects pitch structure by guiding attention to the pitch events that coincide with stressed temporal events. Some empirical support for this model has been provided by Deutsch (1982) and Jones, Boltz, and Kidd (1982). The second explanation suggests, on the contrary, that temporal and pitch information could be perceived independently. Palmer and Krumhansl (1987a, 1987b) have presented some empirical evidence which indicates that the perceived dimensions are processed separately, with the listeners attending to one stimulus dimension at the expense of the other. Studies involving factorial analysis of discrimination tasks (Gabrielsson, 1973; Monahan \& Carterette, 1985) also describe two orthogonal factors (rhythm and pitch), with the former being more fundamental. The idea of independent processing has also been developed by Thomas and Weaver (1975), who proposed two information processing systems, one responsible for analyzing temporal information and an-

The authors are grateful to G. Vallee, F. Leprince, and C. Basso for collecting part of the data. They wish to thank the anonymous reviewers for their helpful criticisms, M. C. Botte for her help in controlling the stimuli and her comments on the paper, and $W$. Jay Dowling, L. Demany, and S. McAdams for their suggestions regarding earlier drafts. Requests for reprints may be sent to Claire Gérard, Laboratoire de Psychologie Expérimentale, Université René Descartes, EPHE, EHESS, URA CNRS 316, 28 rue Serpente, 75006 Paris, France. other responsible for analyzing the characteristics of the sound, such as intensity or pitch.

In this paper, we examine a similar question concerning the perception of musical rhythm. In the same way as the dependence or independence of pitch and duration has been examined, we can ask what the relations between temporal and intensity structures are. Are they also integrated into a single unit (interaction), or is each one processed independently and integrated at a later stage? Although the relations between the two have been described in empirical studies, it is important to go beyond simple description and explain the underlying processes involved (such as perception, attention, and motor control). One of the advantages of developmental studies is that, by studying the way processes progressively emerge and develop, one can glean an understanding of how the same processes work in the adult. In this paper, we will therefore present a series of experiments in which we examined the perception and reproduction of musical rhythms by young children, investigating the psychological processes involved in the extraction of both temporal and dynamic information.

Rhythm is sometimes considered simply to consist of variations in the time domain, with the duration of notes and the interval between the notes influencing the resulting perception of the rhythms. However, variations in many other domains are also known to influence this perception, so that some elements in the rhythm become more perceptually salient or accented than others. Since Cooper and Meyer (1960), many authors (e.g., Thomassen, 1982) have insisted on the fact that dynamic structure can be created by variations in intensity, duration, pitch, and timbre. Handel (1974) classified these various sources of accentuation into two types of organizational principles: 
(1) frequency and intensity patterns, which are patterns in time, and (2) duration and interval patterns, which are patterns of time. He suggested that these two organizational principles may be governed by distinct rules that determine their perception. Monahan and Carterette (1985) classified five major sources of cues of accent: temporal patterning, pitch pattern shape, tonal system, dynamic (loudness) patterning, and timbral patterning. However, much ambiguity exists in the literature concerning words such as "accents," "accenting," and "accentuation." Authors have felt the need to distinguish between the physical dimension of sounds (playing louder, longer, or on a particular instrument) and their psychological dimension (the perception of an event as being more salient than others). To confuse the issue, it is known that although the psychological dimension usually coincides with the physical dimension, accents can be perceived in the absence of any physical variations (subjective accents; see Fraisse, 1956; Povel \& Okkerman, 1981). Monahan and Carterette (1985) defined "accenting" as a psychological event (p. 4), but Monahan, Kendall, and Carterette (1987) referred to physical cues as "accenting" and to perceptual phenomena (whether based on physical variations or not) as "accent." Thomassen (1982) preferred the term "accentuation" for the first and "accent" for the second; Fraisse (1956) wrote of an opposition between objective and subjective accents, the second of which was not based on physical variations; Povel and Okkerman (1981) have called interval-produced "accent" the subjective increment in loudness produced by temporal intervals between two tones. To avoid any confusion in terminology, for this series of experiments, we will use the word accent for variations in the physical dimensions of sound. In this paper, we examine one particular source of accentuation: that of accents created by variations in intensity. Unless otherwise specified, all references to accents will henceforth be directed toward dynamic accents resulting from physical intensity differences.

First, let us examine physical accents. Thomassen (1982) considered that a 4-dB increase in sound level is adequate to make the louder sound be perceived and interpreted as an accent. When Gabrielsson (1974) asked subjects to produce accents on a piano or drum, differences of 2-4 dB and 5-10 dB were observed, respectively. Schmidt (cited in Fraisse, 1956), who asked subjects to tap a regular beat, observed spontaneous grouping with a regular cyclic variation in intensity. The pertinence of dynamics in the perception of music has been demonstrated by Nakamura (1987), who asked musicians to play a piece of music with a crescendo, which was later correctly interpreted by nonmusicians.

As regards subjective accents, psychophysical studies have demonstrated that perceived loudness of tones varies as a function of numerous parameters (such as frequency, duration of tone, or time interval between two tones.) When two tones are presented in short succession, loudness masking occurs. Forward masking appears only when the interval between them is less than 150-200 msec, and backward masking appears when the interval is less than $50 \mathrm{msec}$. Thus, due to the temporal limits given, masking only appears with fast musical tempi. Povel and Okkerman (1981) have also shown that subjective accents are perceived in equitone sequences (frequency, spectral composition, intensity, and duration of tones being constant) in which only the time interval between the tones has been modified. When repeated groups of two tones were presented, subjective accents were perceived on the first or second tone, depending on the duration of the interval between the two. The tendency to hear accents on the last tone of the group only occurred if the betweengroup interval was considerably longer than the withingroup interval and if the latter did not exceed a duration of about $250 \mathrm{msec}$. The strength of the subjective accent seemed high: One subject who was asked to adjust the intensity of the first tone until the two tones sounded equally accented needed an increase of about $4 \mathrm{~dB}$ (Povel \& Okkerman, 1981, Experiment 4). In our experiments, using slower tempi, we could assume that the phenomena of masking and of subjective accentuation would not have much effect on our stimuli-though of course, as will be seen later, they could not be ignored completely.

As we have seen, physical intensity differences constitute an aspect of rhythm that is perceivable and reproducible by musicians and nonmusicians alike. We were therefore surprised with the results of experiments on the perception and reproduction of musical rhythms in young children, because, although temporal structure was often reproduced well, intensity differences were reproduced very rarely (Gérard, 1988a; Gérard \& Auxiette, 1988; Gérard \& Rémond, 1985). The fact that children (up to the age of 8 years) do not spontaneously reproduce systematic variations in intensity could be explained in two ways: One hypothesis (Hypothesis 1) would be that their motor control is inadequate to gauge the strength of beat necessary for the control of the loudness of the taps produced; the other hypothesis (Hypothesis 2) would be that temporal and dynamic information are processed independently, so that attention must be divided between the two. Young children would thus concentrate on one at the expense of the other. If this is the case, it becomes necessary to ask whether temporal or dynamic information receives priority under various conditions, and whether or not the situation changes during development.

We devoted this study to the problem of accentuation in the perception and reproduction of musical rhythms by young children in order to examine these two hypotheses. In the first three experiments, we were concerned with intensity accents; in the fourth experiment, we considered a wider range of phenomena.

\section{EXPERIMENT 1}

One of our aims in Experiment 1 was to examine the relative importance attributed by children to temporal and intensity differences as criteria for judging rhythms (Hypothesis 2). By considering the responses of 5-, 6-, 
7-, and 8-year-old children, one might see how these abilities evolve and whether or not the same importance would always be attributed to the same information.

\section{Method}

Subjects. A total of 120 pupils from a large school complex in Anthony (a suburb of Paris) took part in the experiment. The 30 youngest children came from the last year of nursery school. They were from 5 years to 5 years and 9 months old. The other 90 subjects from the primary school were divided into three age groups: first grade (6 years to 6 years, 9 months), second grade ( 7 years to 7 years, 9 months ), and third grade ( 8 years to 8 years, 9 months). None of the children had a hearing impairment, and "bad pupils" (as judged by the teacher) were excluded from the sample.

Stimuli. Twelve pairs of rhythmic patterns were constructed: 6 pairs with identical patterns (i) and 6 pairs with different patterns (d). Figure 1 presents the patterns, indicating the tempo and, when necessary, the accented sounds. Within a pair, the first rhythm was repeated three times, and then, $2 \mathrm{sec}$ later, the second rhythm was repeated three times. These rhythmic patterns were played by a musician who was asked to tap the accents clearly and more loudly than the other notes when and only when it was indicated in the model (see Figure 1). A wood block was used to obtain a clear staccato sound. The pairs of patterns were recorded on a Sony TCD5M tape recorder. After recording, the pairs were mixed and rerecorded to obtain the three presentation orders, which were designed to prevent the occurrence of more than three is or $d \mathrm{~s}$ in succession and to assure that each pattern appeared at the beginning, middle, and end of the session. At a later date, the actual intervals, intensities, and durations of the sounds used in the experiment were measured by a digital storage oscilloscope (Gould OS 4200 ). The mean duration of the wood-block sounds was $237 \mathrm{msec}$ (range, 200-250 msec), and the interonset intervals corresponded well with
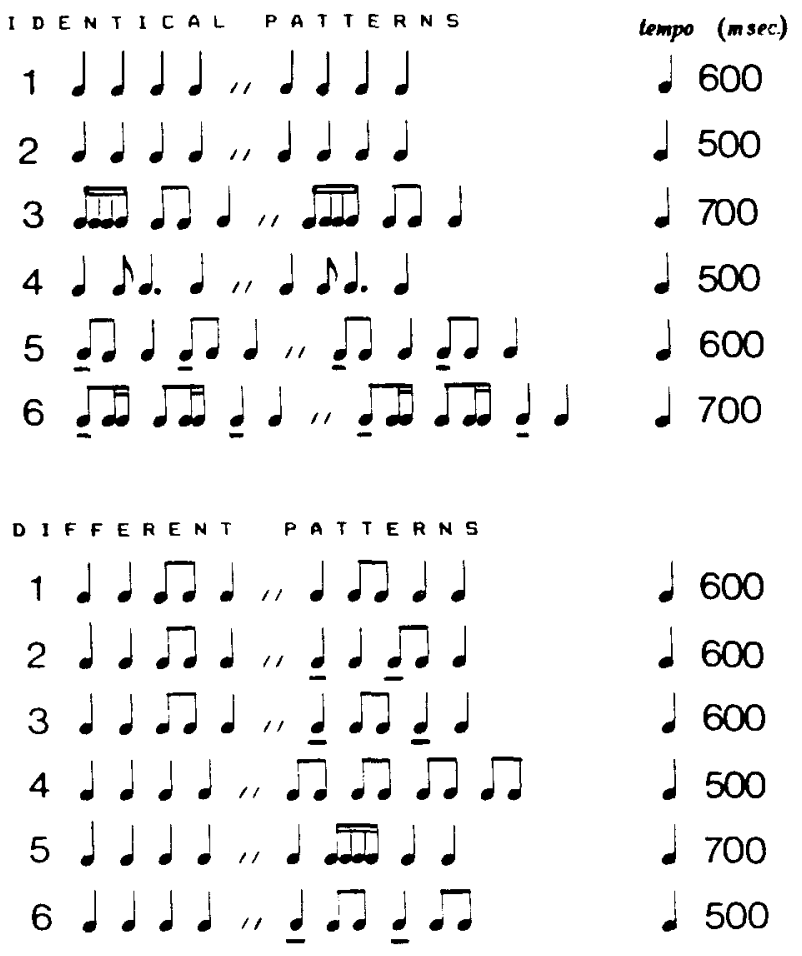

Figure 1. Rhythmic patterns presented in Experiment 1.
Table 1

Percentages of Correct Responses in the Discrimination Task in Experiment 1

\begin{tabular}{|c|c|c|c|c|}
\hline \multirow[b]{2}{*}{ Pair } & \multicolumn{4}{|c|}{ Age Groups } \\
\hline & 5 years & 6 years & 7 years & 8 years \\
\hline \multicolumn{5}{|c|}{ Identical Patterns } \\
\hline il & 86.67 & 83.33 & 83.33 & 100 \\
\hline i2 & 86.67 & 86.67 & 76.67 & 96.67 \\
\hline i3 & 76.67 & 90 & 80 & 93.33 \\
\hline i4 & 60 & 43.33 & 46.67 & 60 \\
\hline i5 & 70 & 86.67 & 90 & 90 \\
\hline i6 & 76.67 & 90 & 90 & 86.67 \\
\hline \multicolumn{5}{|c|}{ Different Patterns } \\
\hline d1 & 53.33 & 86.67 & 63.33 & 90 \\
\hline $\mathrm{d} 2$ & 63.33 & 60 & 60 & 66.67 \\
\hline d3 & 70 & 90 & 90 & 96.67 \\
\hline $\mathrm{d} 4$ & 23.33 & 36.67 & 36.67 & 23.33 \\
\hline d5 & 73.33 & 90 & 83.33 & 100 \\
\hline d6 & 60 & 80 & 93.33 & 90 \\
\hline
\end{tabular}

Note $-\mathrm{i}=$ identical pair, $\mathrm{d}=$ different pair.

the models presented in Figure 1. The variations due to the natural execution performed by the musician were as follows: (1) Interonset intervals were $\pm 7 \mathrm{msec}$ for a quarter note, $\pm 4 \mathrm{msec}$ for an eighth note, and $\pm 3 \mathrm{msec}$ for a sixteenth note; $(2)$ in an unaccented sequence, the greatest difference between the intensity of the softest and that of the loudest sound was 5.7 dB SPL, whereas in an accented sequence, the intensity differences between unaccented and accented sounds were at least $14 \mathrm{~dB}$ SPL (14-19.8 dB). Thus, the manually created sounds had a natural quality, but they were also within the range of values required by the experimenters.

Procedure. The children were examined individually in a quiet room in the school. They sat about $1 \mathrm{~m}$ from the tape recorder and heard the stimuli over a loudspeaker. The following instructions were given to each child: "You are going to hear some music played by Paul and Cecile on their drum. First you will hear Paul's music and then Cecile's music." The experimenter tapped 1.111 .1 . and then $1 \ldots \mid \ldots$ on the table in front of the child. "You see that the 2 pieces of music are not the same. Paul and Cecile don't play the same thing. Listen carefully now." The experimenter tapped $|\ldots||| \mid$ and then $|\ldots||| \mid$ on the table. "Now Cecile and Paul play the same thing, don't they?" (This was done to make sure that the child understood the concepts of "same" and "not the same"). "Now you will hear other pieces of music played by Paul and Cecile. I want you to tell me whether Paul's music is the same or not the same as Cecile's music." The tape recorder was stopped after each pair, and the experimenter noted whether the child considered the two rhythms to be the same or not.

\section{Results}

Table 1 presents the percentage of children who answered the comparisons correctly. Identical patterns were frequently identified correctly with the exception of Pair i4, which contained the only rhythm with a ratio of $1: 3$ between short and long intervals and seemed difficult to encode and recognize as "the same." This phenomenon is well known with respect to both adults (Povel, 1981; Povel \& Essens, 1985) and children (Drake \& Gérard, 1989).

For the different pairs, the results were closely related to the type of difference between the stimuli. When the tempo of isochronous sequences was modified (Pair d4), the children did not consider the two rhythms to be differ- 
ent. Inversely, when an isochronous sequence was compared to a composite rhythm (Pairs d5 and d6), performances were better and improved with age. In this paper, we will focus mainly on the relative importance of temporal and intensive organizations, so Pairs $\mathrm{d} 1, \mathrm{~d} 2$, and $\mathrm{d} 3$ will be considered in detail: In Pair $\mathrm{d} 1$, the two rhythms have a different temporal organization and are not accented; in Pair d2, the two rhythms have the same temporal organization, but one is accented and not the other; in Pair $\mathrm{d} 3$, the temporal and intensive organizations are different. A chi-squared test was used to evaluate significant variations from chance level. Percentages between $36 \%$ and $64 \%$ do not differ from $50 \%$ at the $5 \%$ significance level $(p<.05)$. First, Pair d1, which varied only in temporal structure, was discriminated above chance level only by the 6- and 8 -year-olds, so temporal structure is a dimension along which children were able, in some cases, to discriminate the two rhythms. Sevenyear-old children seemed to have had a failure in performance. These low scores were not related to other behavior observed during the experiment. This apparent failure must be reconsidered in the light of the following observation: The 6-year-old children were very attentive and interested in the experiment. The teacher in the classroom was very proud of this "excellent group, this particular year." So the accident of the curve shows a combined effect of good results for the younger group and poor performances for the older group. The only conclusion we can draw is that for 6- and 7-year-olds, success in the task is not well established and is thus unstable. Second, Pair $\mathrm{d} 2$ can only be discriminated by the presence or absence of accents. Up to the age of 8 , the children considered the two rhythms to be the same, for the scores were below chance level. Intensity differences did not appear to be taken into account. However, the picture was not as simple as this. Pair $\mathrm{d} 3$ had the same temporal difference as $\mathrm{dl}$, but one of the rhythms also had accents. For this pair, discrimination was above chance level for all the children-notably better than for the discrimination of the same temporal structures without accents (Pair d1). The presence of accents enhances the discrimination of temporal structure.

\section{Discussion}

This experiment demonstrates that whereas 5-year-olds apparently do not perceive a difference between two simple rhythms on the basis of either temporal or dynamic information, 8-year-olds are able to use temporal information but neglect dynamic information. However, accents enhance discrimination based on temporal structure for 5- and 7-year-olds. It could be concluded either that accents are not systematically and consciously perceived, or that accents are perceived by the children but are considered unimportant with regard to what makes rhythms similar or different. At least up to the age of 8 , temporal information is dominant while dynamic information is neglected. In order to verify this conclusion (and to be sure that accents are perceived), a second experiment was performed.

\section{EXPERIMENT 2}

Hypothesis 2 states that children can only concentrate on one dimension of rhythm at a time. If temporal structure is reduced to a minimum, enough attention should be released to process information about intensity. It should then be possible for 6-, 7-, and 8-year-old children to discriminate between two sequences on the basis of their intensity differences. What is more, if the problem of sharing attention is eliminated, the role of motor control can be examined (Hypothesis 1). Children were asked to discriminate between two sequences on the basis of intensity differences and to reproduce them.

\section{Method}

Subjects. Pupils in a small private primary school in England took part in Experiment 2. Three age groups (6, 7, and 8 years) of 10 children were examined. None of the children suffered from any hearing impairment.

Stimuli. The sounds were synthezised on a BBC computer and recorded on tape. All the notes were a $\mathrm{C} 3$ on the piano, and they all lasted $40 \mathrm{msec}$. The temporal structure of the rhythmic patterns used was always a regular isochronous beat, but intensity varied; metric accents were introduced. The five basic stimuli are presented in Table 2 . The primary accents were played $50 \%$ louder than the nonaccented notes and the secondary accents $25 \%$ louder (on the linear scale of the computer). All the differences in intensity were easily discriminated by the experimenters. Readings taken at a later date from the oscilloscope gave a difference of $14 \mathrm{~dB}$ SPL between primary accents and unaccented notes and $8 \mathrm{~dB}$ SPL between secondary accents and unaccented notes. Each stimulus contained 12 notes. In $S 1$, all notes were of the same intensity. In $S 2,1$ in every 2 is a primary accent (time signature $=2 / 4$ ). In S3, 1 in every 3 is a primary accent (time signature $=3 / 4$ ). In $S 4,1$ in every 2 notes is accented, alternating between primary and secondary accents (time signature $=4 / 4$ ), and in S5, 1 in every 3 notes is accented, also alternating between primary and secondary accents (time signature $=6 / 8$ ). Fifteen pairs of stimuli were derived by taking the five stimuli two at a time, separated by a pause of $2 \mathrm{sec}$, thus making 5 identical (i) and 10 different (d) pairs as shown in Table 2. The pairs were recorded on a Sony TC-D5M tape recorder.

Procedure. The children were examined individually in a small room in the school. They heard a pair of stimuli over a loudspeaker and were asked to say whether or not the two were the same. Next they heard the first stimulus of the pair again and were asked to

Table 2

Rhythmic Patterns Presented as Stimulus Pairs for Discrimination and Reproduction in Experiment 2

\begin{tabular}{|c|c|c|c|c|c|c|}
\hline \multicolumn{2}{|r|}{ Basic Stimuli } & \multicolumn{5}{|c|}{ Stimulus } \\
\hline Stimulus & Rhythmic Pattern & S1 & $\$ 2$ & S3 & S4 & S5 \\
\hline $\mathrm{SI}$ & UUUUUUUUUUUU & il & dl & $\mathrm{d} 2$ & d3 & d4 \\
\hline S2 & PUPUPUPUPUPU (2/4) & & i2 & d5 & d6 & $\mathrm{d} 7$ \\
\hline S3 & PUUPUUPUUPUU (3/4) & & & $\mathrm{i} 3$ & $\mathrm{~d} 8$ & $\mathrm{~d} 9$ \\
\hline S4 & PUSUPUSUPUSU (4/4) & & & & i4 & $\mathrm{d} 10$ \\
\hline S5 & PUUSUUPUUSUU (6/8) & & & & & i5 \\
\hline
\end{tabular}

Note- $U=$ unaccented; $P=$ primary accent; $S$ without a following numeral $=$ secondary accent $; \mathrm{i}=$ identical pairs; $\mathrm{d}=$ different pairs. Time signatures are indicated between parentheses for S2 to S5. 
Table 3

Percentages of Correct Responses in the Discrimination Task for Identical Patterns in Experiment 2

\begin{tabular}{crrrrrr}
\hline & \multicolumn{5}{c}{ Identical Patterns } \\
\cline { 2 - 6 } Age/Tempo & i1 & i2 & i3 & i4 & i5 & $M$ \\
\hline alt1 & 90 & 80 & 60 & 60 & 60 & \\
alt2 & 50 & 50 & 60 & 90 & 80 & 71 \\
a1t3 & 80 & 50 & 50 & 90 & 90 & \\
a2t1 & 100 & 100 & 80 & 100 & 80 & \\
a2t2 & 70 & 80 & 90 & 60 & 70 & 84 \\
a2t3 & 70 & 90 & 100 & 90 & 80 & \\
a3t1 & 100 & 100 & 90 & 100 & 100 & \\
a3t2 & 80 & 90 & 90 & 80 & 60 & 89 \\
a3t3 & 90 & 100 & 80 & 90 & 90 & \\
Mean & 81 & 82 & 81 & 85 & 79 & 81 \\
\hline
\end{tabular}

Note- $\mathrm{i}=$ identical pair, $\mathrm{a} 1=6$ years; $a 2=7$ years; $\mathrm{a} 3=8$ years. Fast tempo, $\mathrm{t} 1=500 \mathrm{msec}$; medium tempo, $\mathrm{t} 2=600 \mathrm{msec}$; slow tempo, $\mathrm{t} 3=700 \mathrm{msec}$

reproduce it on a drum. Finally, they heard the second stimulus of the pair and reproduced that as well. Three tempi were used, corresponding to three sessions on 3 consecutive days in a counterbalanced order, one tempo at each session: 300,500 , and $700 \mathrm{msec}$ onset to onset. Within a session, the 15 pairs of stimuli were presented in a counterbalanced order. For each subject, each stimulus was heard and reproduced six times in all (e.g., S1 occurred twice in il and once in each of $d 1, d 2, d 3$, and d4), so that six trials were obtained for each child for each stimulus. The whole session was recorded on a second tape recorder, and the reproductions were later analyzed by an analogic extractor of temporal and intensive characteristics (AETIC).

Scoring. The percentage of identical or different pairs correctly identified in the discrimination task was analyzed. Accents were detected in the reproduction task in the following way: For a given subject, each tap was coded as a percentage of the loudest tap, and 10 intensity groups were created. Three categories were defined for each reproduction, depending on the range of intensities used. Taps in the loudest category were considered to be accents.

\section{Results}

Discrimination. The percentage of correct responses for identical pairs are presented in Table 3. The overall success rate was high $(81 \%)$, and performance improved with age [ 6 years $=71 \%, 7$ years $=84 \%, 8$ years $=$ $89 \% ; F(2,27)=3.849, p<.05]$. The fast and slow tempi were easier than the intermediary one [fast $=87 \%$, medium $=73 \%$, slow $=85 \% ; F(2,54)=4.702, p<$ $.05]$. No difference was seen between the pairs, and none of the interactions were significant. However, these results provided no concrete conclusions, since the children might have been making correct identifications on the basis of the total number of notes ( 12 notes) or the total duration of the pattern, rather than the variations in intensity.

Table 4 presents the results for different pairs and shows that the overall success rate on the 10 different pairs was high $(77 \%)$. It improved with age [6 years $=69 \%, 7$ years $=78 \%, 8$ years $=83 \% ; F(2,27)=3.34$, $p<.05$ ], and the fast tempo was easier than the other two [fast $=82 \%$, medium $=75 \%$, slow $=75 \% ; F(2,54)$ $=3.864, p<.05]$. The comparison involved in each pair played an important role. Comparisons of Stimulus 1 (without intensity differences) with the other stimuli were relatively easy $(\mathrm{d} 1=86 \%, \mathrm{~d} 2=88 \%, \mathrm{~d} 3=90 \%$, and $\mathrm{d} 4=92 \%)$ and were of equal difficulty $[F(3,81)=$ 0.757 , n.s.]. Thus, children are indeed able to discriminate metric organization from a simple isochronous beat. The easiest comparison was made between $\mathrm{S} 2$ and $\mathrm{S} 3(\mathrm{~d} 5=95 \%)$, where binary meter was compared with ternary meter. The other comparisons were more difficult, due to the confusions between primary and secondary accents. The results for d6 were very low: S2 and S4, which differed only by the presence of secondary accents, were hardly ever discriminated. In the same way, S3 was confused with $\mathrm{S} 5(\mathrm{~d} 9=20 \%)$, whereas the discrimination between S2 and S5 was easy ( $d 7=93 \%$ ), showing that, in these conditions, the children assimilated the 6/8 time signature with a ternary rather than a binary organization, with the secondary accents being assimilated with primary accents. The same assimilation could explain the high scores for $\mathrm{d} 8(85 \%)$ and $\mathrm{d} 10(83 \%)$.

Table 4

Percentages of Correct Responses in the Discrimination Task for the Different Patterns in Experiment 2

\begin{tabular}{|c|c|c|c|c|c|c|c|c|c|c|}
\hline \multirow[b]{2}{*}{ Age/Tempo } & \multicolumn{10}{|c|}{ Different Patterns } \\
\hline & $\begin{array}{c}\text { d1 } \\
\text { S1S2 }\end{array}$ & $\begin{array}{c}\mathrm{d} 2 \\
\mathrm{~S} 1 \mathrm{~S} 3 \\
\end{array}$ & $\begin{array}{c}\mathrm{d} 3 \\
\text { S1S4 } \\
\end{array}$ & $\begin{array}{c}\mathrm{d} 4 \\
\text { SiS5 } \\
\end{array}$ & $\begin{array}{c}\mathrm{d} 5 \\
\text { S2S3 } \\
\end{array}$ & $\begin{array}{c}\mathrm{d} 6 \\
\mathrm{~S} 2 \mathrm{~S} 4\end{array}$ & $\begin{array}{c}\mathrm{d} 7 \\
\text { S2S5 }\end{array}$ & $\begin{array}{c}\mathrm{d8} \\
\text { S3S4 }\end{array}$ & $\begin{array}{c}\text { d9 } \\
\text { S3S5 }\end{array}$ & $\begin{array}{r}\mathrm{d} 10 \\
\text { S4S5 }\end{array}$ \\
\hline $\begin{array}{l}\text { a } 1 t 1 \\
\text { a } 1+2 \\
\text { a } 1+3\end{array}$ & $\begin{array}{l}90 \\
60 \\
50\end{array}$ & $\begin{array}{l}90 \\
70 \\
80\end{array}$ & $\begin{array}{r}100 \\
70 \\
80\end{array}$ & $\begin{array}{l}90 \\
80 \\
90\end{array}$ & $\begin{array}{r}100 \\
90 \\
90\end{array}$ & $\begin{array}{l}20 \\
20 \\
30\end{array}$ & $\begin{array}{l}90 \\
90 \\
80\end{array}$ & $\begin{array}{l}90 \\
60 \\
70\end{array}$ & $\begin{array}{l}20 \\
30 \\
20\end{array}$ & $\begin{array}{l}70 \\
90 \\
70\end{array}$ \\
\hline $\begin{array}{l}a 2 t l \\
a 2 t 2 \\
a 2 t 3\end{array}$ & $\begin{array}{r}100 \\
90 \\
100\end{array}$ & $\begin{array}{l}90 \\
70 \\
90\end{array}$ & $\begin{array}{r}100 \\
90 \\
70\end{array}$ & $\begin{array}{r}100 \\
90 \\
80\end{array}$ & $\begin{array}{r}100 \\
90 \\
80\end{array}$ & $\begin{array}{l}60 \\
20 \\
60\end{array}$ & $\begin{array}{r}100 \\
90 \\
90\end{array}$ & $\begin{array}{r}100 \\
90 \\
80\end{array}$ & $\begin{array}{r}40 \\
20 \\
0\end{array}$ & $\begin{array}{l}80 \\
90 \\
90\end{array}$ \\
\hline $\begin{array}{l}\text { a3t1 } \\
\text { a3t2 } \\
\text { a3t3 }\end{array}$ & $\begin{array}{r}90 \\
100 \\
90\end{array}$ & $\begin{array}{l}100 \\
100 \\
100\end{array}$ & $\begin{array}{l}100 \\
100 \\
100\end{array}$ & $\begin{array}{l}100 \\
100 \\
100\end{array}$ & $\begin{array}{l}100 \\
100 \\
100\end{array}$ & $\begin{array}{l}40 \\
50 \\
50\end{array}$ & $\begin{array}{l}100 \\
100 \\
100\end{array}$ & $\begin{array}{r}100 \\
80 \\
90\end{array}$ & $\begin{array}{l}10 \\
30 \\
10\end{array}$ & $\begin{array}{r}80 \\
80 \\
100\end{array}$ \\
\hline Mean & 86 & 88 & 90 & 92 & 95 & 39 & 93 & 85 & 20 & 83 \\
\hline
\end{tabular}

Note- $d=$ different pair. $S$ followed by a numeral = stimulus. $a 1=6$ years; $a 2=$ 7 years; $33=8$ years. Fast tempo, $t 1=500 \mathrm{msec}$; medium tempo, $\mathrm{t}=600 \mathrm{msec}$; slow tempo, $\mathrm{t} 3=700 \mathrm{msec}$. 
Reproduction. A reproduction was considered correct if it contained an intensity accent every $2,3,4$, or 6 notes in accordance with the primary accent of the stimulus. Table 5 presents the results. The percentage of correct reproductions increased with age [6 years $=31 \%, 7$ years $=43 \%, 8$ years $=50 \% ; F(2,27)=5.442$, $p<.05]$. The lowest performances were observed in the fast tempo [fast $=35 \%$, medium $=44 \%$, slow $=45 \%$; $F(2,54)=11.179, p<.001)$. The scores also depended on the stimulus $[F(4,108)=36.16, p<.001]$. S1 (without accents) and S2 and S3 (only primary accents) were reproduced correctly more often than were $S 4$ and S5 (which also contained secondary accents). The performances did not improve over the six trials [Trial $1=$ $45 \%$, Trial $2=42 \%$, Trial $3=38 \%$, Trial $4=42 \%$, Trial $5=42 \%$, Trial $6=42 \%, F(5,135)=0.852$, n.s.]. The interaction between age and stimuli $[F(8,108)=$ $2.133, p<.05$ ] is shown in Figure 2. No improvement with age was seen for $S 1[F(1,27)=0.962$, n.s.], but an improvement was seen for all the other stimuli.

\section{Discussion}

Under these simplified temporal conditions of isochronous sequences, from the age of 6 , children were able to discriminate between patterns on the basis of intensity differences. We can conclude that this type of accent is perceived and integrated by young children. When attention does not have to be focused on temporal structure, children are free to concentrate on dynamic aspects of structure. What is more, under these optimal conditions, children from the age of 7 are able to reproduce patterns of accents-their motor control is sufficient to dose the strength of each tap at will for basic patterns of $2 / 4$ and $3 / 4$. Thus, Hypothesis 1 , which postulated inadequate motor control, is invalid, at least from a certain stage of development, and for simple intensive configurations.

\section{EXPERIMENT 3}

Another way to test the attention-sharing hypothesis is to examine the effect of training on various abilities (perception, attention, and motor control). In a reproduction task, it should be possible to draw children's attention to a particular aspect of the rhythm-in this case, the presence of accents-and to see whether or not temporal and/ or dynamic performance improves. It is known that 6year-olds are able to reproduce temporal structures but not dynamic ones, and children of this age were therefore chosen so that we might study whether or not training can enhance performance.

\section{Method}

Subjects. The 23 children who took part in the experiment came from the last year of a Parisian nursery school. Their mean age was 5 years, 10 months ( 5 years to 6 years, 6 months). None of the children suffered from any hearing impairment. "Bad pupils" (as judged by the teacher) were excluded from the sample.

Stimuli. Four rhythmic patterns were constructed. They are presented with their time signatures and their tempi in Figure 3.
Table 5

Percentages of Reproductions Containing Correct Intensity Accents in Experiment 2

\begin{tabular}{|c|c|c|c|c|c|c|}
\hline \multirow{2}{*}{$\begin{array}{c}\text { Age Group/ } \\
\text { Tempo }\end{array}$} & \multicolumn{6}{|c|}{ Trials } \\
\hline & 1 & 2 & 3 & 4 & 5 & 6 \\
\hline \multicolumn{7}{|c|}{ Stimulus S1 } \\
\hline $\begin{array}{l}\text { altl } \\
\text { alt2 } \\
\text { alt3 }\end{array}$ & $\begin{array}{l}60 \\
60 \\
70\end{array}$ & $\begin{array}{l}60 \\
60 \\
70\end{array}$ & $\begin{array}{l}80 \\
40 \\
70\end{array}$ & $\begin{array}{l}60 \\
50 \\
70\end{array}$ & $\begin{array}{l}70 \\
70 \\
80\end{array}$ & $\begin{array}{l}80 \\
60 \\
90\end{array}$ \\
\hline $\begin{array}{l}a 2 t 1 \\
a 2 t 2 \\
a 2 t 3\end{array}$ & $\begin{array}{l}80 \\
60 \\
50\end{array}$ & $\begin{array}{l}80 \\
30 \\
50\end{array}$ & $\begin{array}{l}70 \\
40 \\
60\end{array}$ & $\begin{array}{l}80 \\
50 \\
50\end{array}$ & $\begin{array}{l}50 \\
40 \\
40\end{array}$ & $\begin{array}{l}90 \\
60 \\
60\end{array}$ \\
\hline $\begin{array}{l}a 3 t 1 \\
a 3 t 2 \\
a 3 t 3\end{array}$ & $\begin{array}{l}90 \\
50 \\
40\end{array}$ & $\begin{array}{l}60 \\
80 \\
60\end{array}$ & $\begin{array}{l}50 \\
50 \\
40\end{array}$ & $\begin{array}{l}90 \\
40 \\
40\end{array}$ & $\begin{array}{l}50 \\
70 \\
40\end{array}$ & $\begin{array}{l}80 \\
30 \\
80\end{array}$ \\
\hline Mean & \multicolumn{6}{|c|}{61} \\
\hline
\end{tabular}

Stimulus $\mathbf{S 2}$

\begin{tabular}{|c|c|c|c|c|c|c|}
\hline alt1 & 30 & 20 & 30 & 20 & 30 & 20 \\
\hline alt2 & 30 & 50 & 40 & 30 & 60 & 60 \\
\hline alt3 & 30 & 30 & 40 & 50 & 30 & 40 \\
\hline a2tl & 30 & 50 & 30 & 40 & 40 & \\
\hline $\mathrm{a} 20$ & 60 & 80 & 40 & 50 & 30 & \\
\hline $\mathrm{a} 2 \mathrm{t} 3$ & 80 & 80 & 80 & 80 & 60 & \\
\hline$a 3 t l$ & 60 & 50 & 30 & 60 & 0 & \\
\hline $\mathrm{a} 3 \mathrm{t} 2$ & 60 & 50 & 40 & 50 & 90 & \\
\hline$a 3+3$ & 80 & 90 & 80 & 80 & 80 & \\
\hline Mean & \multicolumn{5}{|c|}{51} & \\
\hline
\end{tabular}

Stimulus S3

$\begin{array}{lrrrrrr}\text { alt1 } & 20 & 20 & 20 & 20 & 30 & 20 \\ \text { alt2 } & 60 & 40 & 60 & 60 & 60 & 50 \\ \text { alt3 } & 40 & 30 & 40 & 30 & 40 & 40 \\ \text { a2t1 } & 40 & 40 & 50 & 50 & 30 & 70 \\ \text { a2t2 } & 80 & 90 & 80 & 70 & 70 & 80 \\ \text { a2t3 } & 100 & 80 & 80 & 70 & 90 & 50 \\ \text { a3t1 } & 80 & 80 & 50 & 40 & 70 & 60 \\ \text { a3t2 } & 80 & 50 & 80 & 100 & 60 & 50 \\ \text { a3t3 } & 70 & 90 & 100 & 90 & 90 & 90\end{array}$

Stimulus S4

alt

a1t2

a1t3

a2t 1

a2t2

a2t3

a 3 t 1

a3t2

a3t3

Mean

$\begin{array}{rrr}0 & 10 & 0 \\ 0 & 30 & 20 \\ 20 & 10 & 0 \\ 30 & 20 & 30 \\ 40 & 20 & 20 \\ 10 & 30 & 20 \\ 20 & 0 & 20 \\ 30 & 50 & 30 \\ 30 & 30 & 10\end{array}$

altl

a 1 t2

alt3

a2t 1

a2t2

a2t3

a3t 1

a 32

a3t3

Mean

10

40

0

20

10

30

10

10
0

40

20

20

10

40

40

0

30

20

40

40

20

20

40

40 22

\section{Stimulus S5}

Note $-\mathrm{a} 1=6$ years; $\mathrm{a} 2=7$ years; $\mathrm{a} 3=8$ years. Fast tempo, $\mathrm{tl}=$ 500 msec; medium tempo, $t 2=600 \mathrm{msec}$; slow tempo, $\mathrm{t} 3=700 \mathrm{msec}$. 


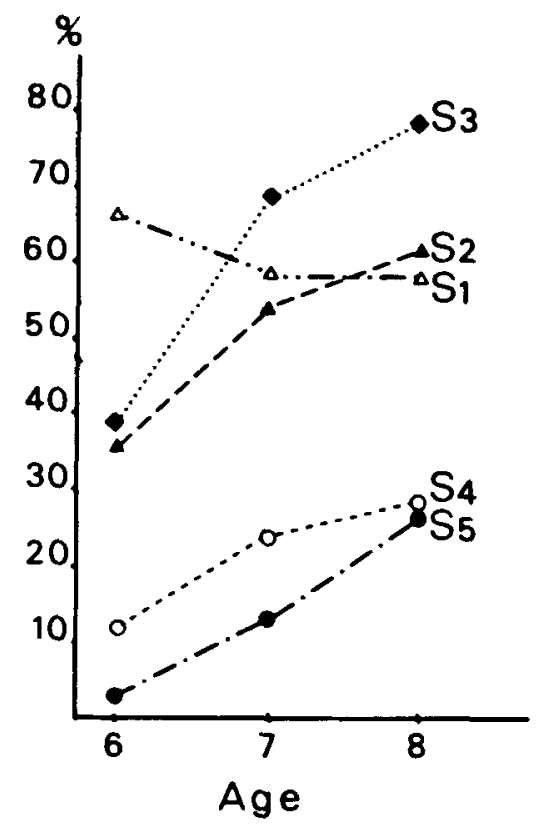

Figure 2. Evolution with age of the percentage of correct reproductions of intensity differences in Experiment 2.

The patterns were played on a wood block by a musician who was asked to tap all the metric accents clearly and more loudly than the other notes. This procedure of hearing and reproducing wood-block sounds makes stimuli and responses as similar as possible and approximates "real" musical situations in terms of type of sounds as well as type of movement. The patterns were recorded on a Sony TC-D5M tape recorder. The actual intervals, intensities, and durations of sounds produced by the musician were measured by the oscilloscope as in Experiment 1. Once again, the temporal intervals corresponded well with those required (mean variations were $\pm 10 \mathrm{msec}$ for a quarter note, $\pm 5 \mathrm{msec}$ for an eighth note, and $\pm 3 \mathrm{msec}$ for a sixteenth note). The smallest difference between accented and unaccented sounds in a given sequence was $12 \mathrm{~dB}$ SPL $(12-15.6 \mathrm{~dB})$. The mean duration of the sounds was $228 \mathrm{msec}$.

Procedure. The children were examined individually in a quiet room in the school. They heard a first pattern and were asked to reproduce it on a wood block. Their attention was then drawn to the dynamic structure of the rhythms by saying, "Listen carefully, some beats in the 'music' are louder than others. If you hear a loud beat, hit louder, and if you hear a soft beat, hit softer too." Following these instructions, the children were asked to hit the table three times "loudly" and three times "softly," and then to alternate loud and soft beats for a cycle of a dozen beats. Then a rhythm was presented three times, the child being asked to reproduce it after each presentation. The presentation order was counterbalanced. The whole session was recorded on a tape recorder.

Scoring. The temporal structure was scored by two independent judges as follows: $0=$ a simple pulse or temporal structure different from the model; 1 = part of the temporal structure reproduced; $2=$ correct temporal structure. Intensity reproductions were studied by the AETIC and decoded by computer, as described for Experiment 2 .

\section{Results}

Intensity reproductions. First, recall that in Experiment 2 no improvement in the reproduction of accents was observed over trials. Similar results have been found by
Gérard and Rémond (1985) with more complex temporal structures. Once again, in Experiment 3, accents were either absent from the reproductions or anarchic (i.e., with no apparent correspondence to the intensity differences in the models). The analyses issued from AETIC decoding were inconsistent. This was true for the trials both before and after accents were explained. The warnings between Trials 1 and 2 resulted in greater general loudness of all the reproduced taps, but not in precise metric accents localization. Out of the 23 children examined, only 11 reproduced audible accents, and only 6 (out of the 11 ) did so with an acceptable temporal structure; the other 5 children reproduced isochronic pulses or repeated patterns of three taps, whatever the stimulus. As a consequence, the good scores for temporal reproductions corresponded mainly to unaccented reproductions. Analyses performed on the 6 subjects who had accented some taps also showed that the reproduced accents did not conform either to the metric accents of the stimulus or to any other systematic choice. The total number of accents increased on the second trial (13 taps accented for the 6 subjects $\times 4$ patterns on the first trial, 28 taps accented for the 6 subjects $\times 4$ patterns on the second, 26 on the third and 22 on the fourth), but the accents were equally distributed on each tap of the patterns. Therefore, because the number of observations was too low and even the slightest trend toward systematic behavior was absent, the study had to be abandoned.

An explanation is required. As described in the introduction, in Povel and Okkerman's (1981) research an "interval-produced accent" occurred with temporal patterns containing repeated groups of two tones (e.g., II. II.). These patterns are hard to perform when the metric accent corresponds to the short first tone (as observed by the authors, using two examples, p. 571). In our experiments, we never employed such two-tone patterns, but two patterns in the present experiment (among the 22 different patterns presented in Experiments 1, 2, and 3) began with a series of short tones $(1.1 .1 \ldots$ or $11111 \ldots)$. If the "interval-produced accent" could be generalized to groups of more than two tones, the introduction of metric accents could have made our sequences ambivalent, with the metric accent on the first tone of the group and the interval-produced accent on the last long tone. However, Povel and Okkerman demonstrated that interval-

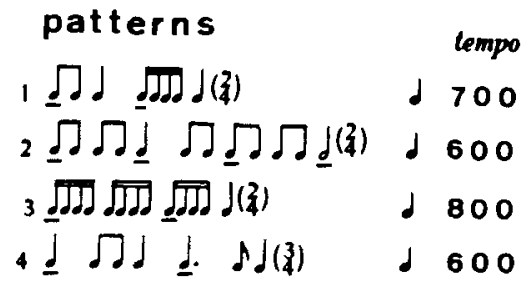

Figure 3. Rhythmic patterns presented in Experiment 3. For each pattern, the time signature is indicated in brackets and the interonset interval between two quarter notes is given in milliseconds. 


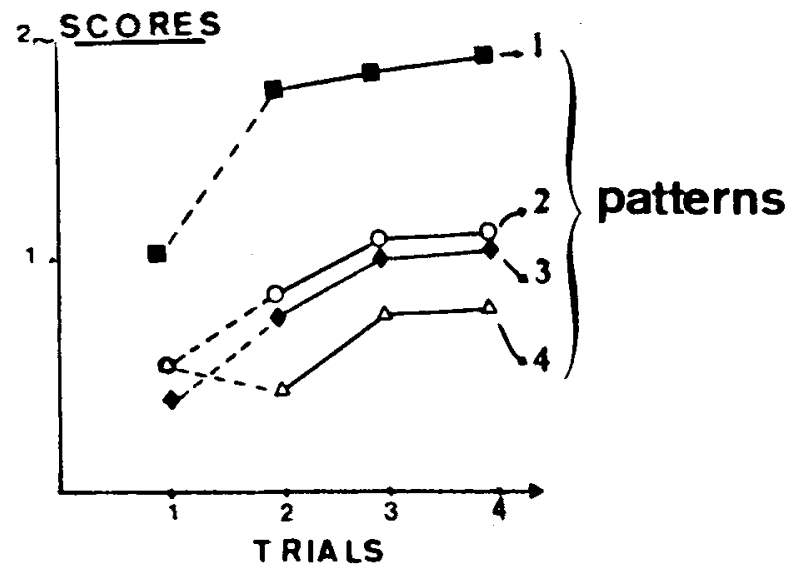

Figure 4. Improvement in the temporal structure of the reproductions over trials in Experiment 3. The child's attention is drawn to the accents between Trials 1 and 2 .

produced accents disappear if the interval following the short tone is longer than $250 \mathrm{msec}$. With our relatively slow tempi, we were probably out of the range of the phenomenon. Nevertheless, we are currently reproducing Povel and Okkerman's experiment with longer groups of tones and with children to verify this point.

A final related point must be mentioned. Povel and Essens (1985) asserted that the initial and final tones of a cluster consisting of three or more tones were perceptually marked. In this case, metric accents would reinforce this trend and not conflict with it, but the question still remains: Why don't young children reproduce accents?

Temporal structures. Figure 4 presents the improvements of the scores over trials. For temporal structure, the figure shows that for three of the four rhythms used, a greater improvement was observed between the first and second reproductions (when the child's attention was drawn to the presence of accents) $[F(3,198)=17.542$, $p<.05]$ than between the other trials, where very little improvement was observed $[F(1,198)=0.071$, n.s. $]$. Once again, this confirms the ineffectiveness of simple repetition without changing the child's cognitive strategy.

\section{Discussion}

Experiment 3 shows that it is possible to direct a child's attention toward the dynamic structure. Although accents were still not directly reproduced, the children must have taken them into account, for when attention was drawn to them, the reproduction of the temporal structure improved. This result contradicts Hypothesis 2, since variations in one dimension (intensity) influence the perception of variations in the other dimension (time), demonstrating a certain degree of interaction, as in Experiment 1. We will come back to this very interesting observation in the general discussion.

\section{EXPERIMENT 4}

In the first three experiments, dynamic structure was limited to variations in intensity, but as stated in the introduction, other events can create accents in "real" music. Lerdahl and Jackendoff (1983a, 1983b) distinguish three types of accents: phenomenal accents (events on the musical surface that give emphasis or stress to a moment in the musical flow, such as sudden changes in dynamics or timbre, leaps to relatively high or low notes, or harmonic changes), metric accents (the periodic return of any beat that is relatively strong in its metrical context), and structural accents (the conjunction of melodic, harmonic, or metric events). In Experiment 4, we examined children's ability to synchronize with the metric structure of Tchaikovsky's Sugar Plum Fairy. Once again, Hypothesis 2, regarding separate cognitive channels, was tested, but this time two possibilities were considered. Either phenomenal and structural accents enhance the metric structure of the music, making it more easily perceivable and thus helping synchronization, or they distract the children's attention from the temporal structure they are trying to follow, thus disrupting synchronization. In the latter case, attention has to be shared between different sources of information. This time, "real" music will be examined.

In Experiment 4, 5.5-year-old children were selected, for two reasons. The first, as previously seen, was tied to the critical period of development (between ages 5 and 6), and the second was related to the fact that, at this age, children are known to be able to synchronize easily with a regular beat. Dowling and Harwood (1986) and Moog (1976) consider that synchronization is achieved at the age of about 3 or 4 years. We wanted to see whether this behavior would be observed in situations more complex than those observed by these authors, who had children accompany their own singing of familiar songs.

\section{Method}

Subjects. Thirty-three children with a mean age of 5.5 years (range, 5-6 years) were selected from the upper classes of a nursery school in Rouen. They were considered by the teacher to have normal hearing and to be "good pupils."

Procedure. During the week preceding the experiment, an afternoon was spent getting the children used to the videotape recorder (Sony Camescope VT 8 AF). The children were filmed in the school library during group games with the teacher. The camescope was left in the room for a week. On a separate day, the children listened to the Sugar Plum Fairy Dance (played by the London Symphony Orchestra under the direction of Antal Dorati; a Philips stereo recording) twice in succession. The following week, they were examined individually in the school library and asked to accompany the Sugar Plum Fairy music by clapping their hands. Each child was sitting on a chair in front of the camera, the experimenter asked if the child was ready; and when the child was, a TC-D5M tape recorder played the music and the camescope recorded the session.

Scoring. First, the sound events of the music were coded with the computer by marking the beginning of the piece, the metric structure, the theme variations, the beginnings and ends of the melodic 
phrases, and the expressive variations in intensity tied to the interpretation. All of these marked events were digitally coded 0 or 1 and located along a temporal chain corresponding to the unfolding of the music. From this information, structural accents were derived, which were defined, in the context of this experiment, in terms of the simultaneous occurrence of at least two events. Next to this were plotted the periods of synchronization and desynchronization observed by two independent judges for each child. The musical piece contained:

A metric introduction ( $7 \mathrm{sec}$ ) given by the strings;

Theme 1 (T1), the appearance of two melodic phrases over the metric by the celesta $(15.5 \mathrm{sec})$;

Theme $2(\mathrm{~T} 2)$, the repetition and development of the same melody without the underlying metrics $(13.5 \mathrm{sec})$;

Theme 3 (T3), the succession of seven short melodic phrases; Theme 4 (T4), an arpeggiated transition $(9 \mathrm{sec})$;

Theme 5 (T5), the repetition of T1;

Theme 6 (T6), the repetition of $\mathrm{T} 2$.

\section{Results}

Table 6 presents the mean percentage of total desynchronization time during each theme. Synchronization with the introductory "metric" was almost perfect for all children. Half the children beat the quarter note when the other half beat the eighth note, but in both cases the beats were very regular and well synchronized. Desynchronization appeared when the metric disappeared at the end of $\mathrm{T} 1$ and during $\mathrm{T} 2$, even though the melody was the same. Desynchronizations were also frequent in T3. This is surprising, since the main musical line and the short melodic phrases were very regular. Only T4 had a more fluid organization, so it is not surprising that it was accompanied by almost $40 \%$ desynchronization time.

It was also possible to determine at what point in the music the desynchronizations started by examining the sequence of coded musical events and the parallel sequence of desynchronization. This analysis showed that desynchronizations were particularly numerous when expressive variations in intensity appeared; increasing intensities, far from regularizing beats, had a destabilizing influence. Moreover, the beginnings and ends of melo-

Table 6

Percent Desynchronization Time During Each Theme in Experiment 4

\begin{tabular}{lcl} 
Theme & $\begin{array}{c}\text { \%Desynch. } \\
\text { Time }\end{array}$ & Difference \\
\hline T1 & 7 & \\
T2 & 19.7 & $F(1,15)=5.007, p<.05$ \\
T5 & 8.7 \\
T6 & 22 & \\
& & \\
T3 & 29.7 \\
T4 & 39 & $F(1,15)=4.317, p<.05$ \\
& & n.s.
\end{tabular}

T1, T2, T5, T6

T3, T4

$F(1,15)=13.262, p<.01$

Note-T 1 and $\mathrm{T} 2$ have the same melodic lines but metric accompaniment disappears in $\mathrm{T} 2$. This difference is repeated in $\mathrm{T} 5$ and $\mathrm{T} 6 . \mathrm{T} 3$ and $\mathrm{T} 4$ are composed differently: small melodic phrases in T3, arpeggios in T4. These two last themes do not differ from each other but do differ from T1 T2 T5 T6 together. dies disturbed synchronization too. Since structural accents were derived from the conjunction of several important events, it could be predicted that they should disturb performances as well. This was indeed observed.

\section{Discussion}

Structural accents are the conjunction in time of several important events in the music, so it could be predicted that if they drew attention to a particular point in time, children would find it easier to synchronize with the music. The opposite effect was found; when several events occurred simultaneously, the children lost track of the metric structure of the music. This could be interpreted by the fact that more processing time is required when more information arrives simultaneously and ongoing activity is thereby inhibited. In this real-life music situation, expressive structure of a piece of music camouflages the metric structure.

\section{GENERAL DISCUSSION}

In developmental studies of rhythm perception, researchers have concentrated on the perception of temporal structure. It is significant that hardly anyone, even those who have carried out considerable studies of children, refers to the perception of accents (Dowling \& Harwood, 1986; Hargreaves, 1986; Sloboda, 1985; Zenatti, 1981). Can we therefore conclude that children (and indeed the researchers we have just mentioned) consider accents to be unimportant?

The starting point for this series of experiments was our observation that 6-year-olds are able to reproduce simple temporal structures, but that even 8-year-olds do not reproduce intensity differences. We have shown that this inability cannot be explained by problems of motor control, since under optimal conditions (Experiment 2) 7year-olds can sufficiently control the intensity of their taps at will. In a similar way, from the age of 6 , children are able to discriminate between two sequences that vary in temporal structure, but even 8-year-olds are not able to discriminate on the basis of accentuation alone in complex temporal structures (Experiment 1). We exclude the possibility that children are unable to hear the differences in intensity between the loud and soft taps, since, under optimal conditions (Experiment 2), they are able to discriminate on the basis of metric accents. In other words, children are able to hear and reproduce accents, but they do not do this spontaneously before the age of 8 , and, even then, they do so inefficiently. We have also seen that even if accents are neither considered important by themselves nor reproduced, they do help to structure the temporal aspects of a rhythm (Experiments 1 and 3). So accents enhance the perceptual organization of a rhythm. We therefore need to explain how accents can play such a role.

The periodic occurrence of accents is not only a cue for segmentation into groups (Cooper \& Meyer, 1960; Deliège, 1987; Teplov, 1966), but also the basis of met- 
ric organization (Cooper \& Meyer, 1960). Consequently, perhaps by underlying the grouping or metric structure of rhythm, accents allow a higher level of perceptual hierarchy. It would therefore be interesting to examine formal analyses of the hierarchical structure of music (Lerdahl \& Jackendoff, 1983a, 1983b; Longuet-Higgins \& Lee, 1984) in the light of developmental studies. But these formal considerations do not explain the psychological processes involved, which will be discussed now.

In some psychological studies, it has been suggested that melody and rhythm are processed independently; likewise, we have suggested that accentuation and temporal aspects of rhythm are processed independently. Although we have seen that young children are able to concentrate on the dynamic dimension alone (Experiment 2), we have also seen that the presence of intensity accents influences the perception of the temporal structure of the rhythms (Experiments 1 and 3), demonstrating a certain degree of interaction. We can therefore reject the now dated notion of two separate channels (one for intensity and one for time) with independent processing. In its place appears the notion of independence in response organization; it is as if the children were unable to concentrate on both aspects of rhythm at the same time. Our findings can be explained in relation to studies of divided attention and characteristics of attentional resources.

Historically, the first explanations of attentional selectivity (in the framework of "filter models") emphasized the richness and complexity of the information presented at one time, along with the risk of overload (Broadbent, 1958). Filter models of attention tend today to have been replaced by "resource capacity models" (Kahneman, 1973; Kahneman \& Treisman, 1984). If we consider the concept of resource in the sense used by Norman and Bobrow (1975), resources include "such things as processing effort, various forms of memory capacity, and communication channels"' (p. 45). The term resource is mainly reserved for the fuel metaphor, yet Hirst (1986), Hirst and Kalmar (1987), and Hirst, Spelke, Reaves, Caharack, and Neisser (1980) consider (1) that cognitive structures and skills are resources; (2) that resources must differ along stimulus and response dimensions; and (3) that the number of distinct resources is not fixed, but can change with subjects' practice and experience. These theoretical considerations fit well with our results.

Easy and adequate execution of our tasks will depend on the complexity of the material, the subject's familiarity with this material, and the degree of maturation of the system. As expertise (acculturation, learning, maturation) increases, less processing time is required. Thus, for musicians with a high degree of expertise, processing occurs in an automatic fashion and requires little attention. Reproduction of both temporal and dynamic structure can be realized effectively. However, for young children, who have not as yet developed the necessary expertise, each type of execution requires considerable attention, so they concentrate on either one or the other of the aspects of the stimulus, not on both. We have seen that temporal structure seems to be more fundamental than accent structure when accent structure reinforces the metric one; when two types of information are in competition, priority for attention is given to temporal aspects. However, when dynamic structure is considered within a larger framework, as in Experiment 4, we have also seen that dynamic information can upset temporal structure.

The question of how this expertise might be acquired is complex. First, it could be that maturation is sufficient for the cognitive processes to become functional. Second, acculturation (passive acquisition of musical laws through exposure to music) could explain how children gradually acquire the necessary rules. Finally, active learning could be necessary for the acquisition of certain abilities; without training, these abilities might never be acquired. Some experiments on the role of musical competence in rhythm reproduction have shown that active learning improves dynamic structuration more than temporal structuration (Gérard, 1988b; Gérard, Drake, \& Auxiette, 1990). New experiments on the relative abilities of 6- and 8-year-old children, adult nonmusicians, and adult musicians regarding temporal and dynamic structure should clarify this point (Drake \& Gérard, 1990).

Let us end on a musical note. We have seen that temporal information rather than periodic accent is more fundamental in children; the abilities involved in perception seem to develop at an earlier age for the former. A parallel can be drawn with the history of western music. The rhythmic structure of religious chants was based on the dynamics of speech. A repetitive, regular intensity structure attesting to a metric organization only appeared later, when popular dance music won the status of "music" (Lachartre, 1985). Moreover, if we examine a musical score today, temporal information is clearly indicated (the length of each note in relation to the others is explicit; the tempo is stated), whereas dynamic structure is left much more to the musician's intuitive knowledge of the accents involved in both metric and grouping structures. Perhaps everyone can produce a temporal structure, but only musicians are able to reconstitute it with the appropriate dynamic structure that will make it a living, musical rhythm.

\section{REFERENCES}

Broadbent, D. E. (1958). Perception and communication. London: Pergamon.

COOPER, G., MEYer, L. B. (1960). The rhythmic structure of music. Chicago: University of Chicago Press.

DELIĖGE, I. (1987). Grouping conditions in music listening: An approach to Lerdahl and Jackendoff's grouping preference rules. Music Perception, 4, 325-360.

DEUTSCH, D. (1982). The internal representation of information in the form of hierarchies. Perception \& Psychophysics, 31, 596-598.

Dowling, W. J., HaRwood, D. L. (1986). Music cognition. Orlando, FL: Academic Press

Drake, C., \& Gérard, C. (1989). A psychological pulse train: How young children use this cognitive framework to structure simple rhythms. Psychological Research, 51, 51.

DRAKE, C. \& GÉRARD, C. (1990). The reproduction of simple rhythms 
by children and adults (musicians and nonmusicians) is improved by the introduction of intensity accents. Manuscript in preparation.

Fraisse, P. (1956). Les structures rythmiques. Louvain: Publications Universitaires de Louvain.

GABRIELSSON, A. (1973). Similarity ratings and dimension analyses of auditory rhythm patterns: I. Scandinavian Journal of Psychology, 14, 138-160.

Gabrielsson, A. (1974). Performance of rhythm patterns. Scandinavian Journal of Psychology, 15, 63-72.

Gérard, C. (1988a). L'enfant et le rythme: Études expérimentales de la discrimination et de la reproduction de rythmes musicaux. Vibrarions, 6, 70-105.

GÉRARD, C. (1988b). Perception du temps et du rythme: L'enfant dispose-t-il d'une horloge interne? Marsyas: Revue de l'Institut de Pédagogie Musicale et Chorgrégraphique, 8, 75-85.

GÉRARD, C., AUXIETtE, C. (1988). The role played by melodic and verbal organisation in the reproduction of rhythmic groups by children. Music Perception, 6, 173-192.

Gérard, C., Drake, C., Auxiette, C. (1990). The role played by musical competence in the reproduction of rhythmic patterns by children. Unpublished manuscript.

GÉRARD, C., RÉMOND, C. (1985). Evolution génétique des reproductions rythmiques selon les conditions de présentation du modèle. Un published master's thesis, Laboratoire de Psychologie Experimentale, Paris V.

HaNDEL, S. (1974). Perceiving melodic and rhythmic auditory patterns. Journal of Experimental Psychology, 103, 922-933.

HARGReAves, D. J. (1986). The developmental psychology of music. Cambridge, England: Cambridge University Press.

Hirst, W. (1986). Aspects of divided and selective attention. In J. Ledoux \& W. Hirst (Eds.), Mind and brain (pp. 105-141). New York: Cambridge University Press.

HiRst, W., KALMAR, D. (1987). Characterizing attentional resources. Journal of Experimental Psychology: General, 116, 68-81.

Hirst, W., Spelke, E., Reaves, C., Caharack, G., Neisser, U. (1980). Dividing attention without alternation or automaticity. Jour nal of Experimental Psychology: General, 109, 98-117.

JoNEs, M. R. (1976). Time, our lost dimension: Toward a new theory of perception, attention and memory. Psychological Review, 83, 323-355.

JONES, M. R. (1987). Dynamic pattern structure in music: Recent theory and research. Perception \& Psychophysics, 41, 621-634.

JONES, M. R., BoLtZ, M., KIDD, G. (1982). Controlled attending as a function of melodic and temporal context. Perception \& Psychophysics, 32, 211-218.

Kahneman, D. (1973). Attention and effort. Englewood Cliffs, NJ: Prentice Hall.

KAhNEMAN, D., \& TrEisman, A. (1984). Changing views of attention and automaticity. In R. Parasuraman \& D. R. Davies (Eds.), Varieties of attention (pp. 29-61). New York: Academic Press.
LACHARTRE, N. (1985). Mesures musicales. In Encyclopaedia Universalis (pp. 1225-1227). Paris: Encyclopédie Universalis.

LERDAHL, F., JACKENDOFF, R. (1983a). A generative theory of tonal music. Cambridge, MA: MIT Press.

LERDAHL, F., JACKENDOFF, R. (1983b). An overview of hierarchical structure in music. Music Perception, 1, 229-252

Longuet-Higgins, H. C., \& LeE, C. S. (1984). The rhythmic interpretation of monophasic music. Music Perception, 1, 424-441.

MooG, H. (1976). The musical experience of the preschool child (C. Clarke, Trans.). London: Schott.

Monahan, C. B., Carterette, E. C. (1985). Pitch and duration as determinants of musical space. Music Perception, 13, 1-32.

Monahan, C. B., Kendall, R. A., Carterette, E. C. (1987). The effect of melodic and temporal contour on recognition memory for pitch change. Perception \& Psychophysics, 41, 576-600

NAKAMURA, T. (1987). The communication of dynamics between musicians and listeners through musical performance. Perception \& Psychophysics, 41, 525-533.

Norman, D. A., Bobrow, D. J. (1975). On data-limited and resourcelimited processes. Cognitive Psychology, 7, 44-64.

Palmer, C., Krumhansl, C. L. (1987a). Independent temporal and pitch structures in determination of musical phrases. Journal of Experimental Psychology: Human Perception \& Performance, 13. 116-126.

Palmer, C. \& Krumhansl, C. L. (1987b). Pitch and temporal contributions to musical phrase perception: Effects of harmony, performance timing, and familiarity. Perception \& Psychophysics, 41. 505-518.

POVEL, D. J. (1981). Internal representation of simple temporal patterns. Joumal of Experimental Psychology: Human Perception \& Performance, 7, 3-18

Povel, D. J. E Essens, P. (1985). Perception of temporal patterns Music Perception, 2, 411-440.

Povel, D. J., OKKerman, H. (1981). Accents in equitone sequences Perception \& Psychophysics, 30, 565-572.

SLOBOdA, J. A. (1985). The musical mind: The cognitive psychology of music. Oxford, England: Clarendon Press.

Teplov, B. M. (1966). Psychologie des aptitudes musicales. Paris: Presses Universitaires de France.

Thomas, E. A. C., Weaver, W. B. (1975). Cognitive processing and time perception. Perception \& Psychophysics, 17, 363-367.

Thomassen, J. M. (1982). Melodic accent: Experiments and a tentative model. Journal of the Acoustical Society of America, 71, 1596-1605.

Zenatti, A. (1981). Lenfant et son environnement musical. Paris: Presses Universitaires de France.

(Manuscript received March 30, 1989; revision accepted for publication January 31, 1990.) 